\title{
Nutritional Condition among Children Less than 5 Years Old in AL-Najaf City
}

\author{
Yasser Hatef Hedawi ${ }^{1}$, Sarah HatimAjeel ${ }^{2}$ \\ ${ }^{I}$ R.N. Community Health Nursing, ${ }^{2}$ Assist. Lecturer, Nursing Department, Altoosi University College, Iraq
}

\begin{abstract}
Background: A good nutrition is an essential component of good health. Malnutrition is known contributing factors to diseases and death. In the developing world, malnutrition affects approximately 800 million people, greater than 340 million whom are children under the age of five years. Over six million of those children die every year from malnutrition ${ }^{(2)}$.
\end{abstract}

Objectives: The study aims at assess the domains of nutritional status in term of (weight and height for age) through anthropometric measurements.

Methodology: A descriptive/Cross-sectional study is conducted throughout the period of October $1^{\text {st }} 2019$ to June $17^{\text {th }} 2020$ in order to nutritional status for children less than 5 years old in AL-najaf city in terms of (weight and height for age) through anthropometric measurements. And also, to find out the relationships between child's and mother's demographic characteristics and nutritional status.

A non-probability convenience sample of (1000) children with their mothers visiting the primary health care centers. This sample is distributed throughout two primary health care sectors according to Najaf Health Directorate. A total of (10) primary health care centers is selected for the purpose of the study. A pilot study was conducted and the questionnaire validity was achieved through a panel of (17) experts.

Results: The majority of children were normal with assessed regard the nutritional status by weight for age indicators, as well as, nutritional status assessed through height for age and weight for height nutritional indicators. Some socio-demographic characteristics influenced children nutritional status, especially the mother educational, level economic status of the family and breast feeding.

Conclusions: The majority of study sample recorded normal nutritional status according to all three nutritional indicators; weight for age (WAZ), weight for height (WHZ), and height for age (HAZ).

Recommendations: Nutrition counseling and education to the mothers is an important component on health services which would help to decrease the effect of ignorance and faulty cooking or dietary practices. As well as proper feeding, home health care, food preparation, hygiene.

Keywords: Assessment, Nutritional condition, Children less than 5 years.

\section{Introduction}

In Iraq there are several studies that are conducted in regarding the assessment of nutritional status in different children groups and different geographical areas, results reveals that nutritional status may affected the children health ${ }^{(1)}$. Malnutrition conceded single of the chief problems in community wellbeing challenges in developed countries. Regularly refer on the way to a silence urgent situation cases, it has devastation special effects resting on offspring especially under five years, society and future human-kind. It is several of the factor that strength give explanation the reason of such widely spread mal-nutrition in children low down delivery weight, inadequate provisions of nutrients, commonness of communicable disease, not have of breastfeeding, in addition to inappropriate child care ${ }^{(2)}$. 
Assessment of nutritional status for under five years' children are monitored by the use of anthropometric measurements, specifically height and weight (BMI), which in combination with the age of the child forms the anthropometric indices. These are further classified as weight-age, measurement lengthwise or tallness-age, weight-measurement lengthwise or tallness in addition to body gathering guide-age ${ }^{(3)}$. The causes of under nutrition are diverse but in most cases include some degree of quality or else quantity of foodstuff, suboptimal feed practice, in addition to elevated tariff of communicable diseases ${ }^{(4)}$. The consideration of dietary condition of children be a necessary element of monitor physical condition in increasing countries. Early identification of whichever relating to diet problem is fundamental for the reason that, family unit, teacher, community psychotherapy as well as treatment interference are additional to be expected previous to undernourishment be converted into not as good as. The World Health Organization (WHO) estimate that a number of 3 billion populaces be ill with undernourishment of one type or other ${ }^{(5)}$. The better nutrition means immune systems stronger, due to fight infectious diseases and a lesser amount of ill health, enhanced wellbeing status as well as a community fruitful. Self-determination commencing lack of food in addition to undernourishment is a essential individual rights as well as their improvement is a basic precondition used for individual in addition to nationwide progress ${ }^{(6)}$.
Objectives: The study aims to assess the domains of nutritional status in term of (weight and height for age) through anthropometric measurements.

\section{Methodology}

A descriptive/Cross-sectional study is conducted throughout the period of October 1st 2019 to June 17th 2020 in order to nutritional status for children less than 5 years old in AL-najaf city in terms of (weight and height for age) through anthropometric measurements. And also, to find out the relationships between child's and mother's demographic characteristics and nutritional status.

A non-probability convenience sample of (1000) children with their mothers visiting the primary health care centers. This sample is distributed throughout two primary health care sectors according to Najaf Health Directorate. A total of (10) primary health care centers is selected for the purpose of the study. A pilot study was conducted and the questionnaire validity was achieved through a panel of (17) experts. Data were analyzed through the application of descriptive statistical data analysis approach that includes, frequencies and percentages; and inferential statistical data analysis approach that include Chi-squared test.

\section{Results}

Table 1: Distribution of the Study Sample by their Demographic Data for Children

\begin{tabular}{|l|c|c|}
\hline Child Demographic Data & Frequency N=1000 & Percentage \\
\hline Gender & 527 & 52.7 \\
\hline Male & 473 & 47.3 \\
\hline Female & $\mathbf{1 0 0 0}$ & $\mathbf{1 0 0 \%}$ \\
\hline Total & \multicolumn{2}{|c|}{} \\
\hline Age (months) & 82 & 8.2 \\
\hline One hour- 10 & 122 & 12.2 \\
\hline $11-22$ & 530 & 53 \\
\hline $23-34$ & 180 & 18 \\
\hline $35-46$ & 86 & $\mathbf{1 0 0 \%}$ \\
\hline $47-60$ & $\mathbf{1 0 0 0}$ & 44.8 \\
\hline Total & \multicolumn{2}{|c|}{} \\
\hline Types of Feeding & 448 & $\mathbf{1 0 0 \%}$ \\
\hline Breast feeding & 552 & $\mathbf{1}$ \\
\hline Mixed feeding(bottle feeding) & $\mathbf{1 0 0 0}$ & \\
\hline Total & & \\
\hline
\end{tabular}


This table depicts that the gender, those who were male in the study sample accounted (52.7\%) and those who were female accounted for (47. 3\%).Concerning children age in the study, the majority of them was
(23-34) months which accounted (53\%). The child's feeding pattern of mothers in the study was distributed as $(44.8 \%)$ for breast feeding babies; and (53\%) for mixed feeding.

Table 2: Distribution of the Study Sample by their Demographic Data for Mothers

\begin{tabular}{|c|c|c|}
\hline General Information (Mothers' Data) & Frequency $N=1000$ & Percentage \\
\hline \multicolumn{3}{|l|}{ Mother Education Level } \\
\hline Not able to read and write & 294 & 29.4 \\
\hline Read and write & 158 & 15.8 \\
\hline Primary school & 396 & 39.6 \\
\hline Middle school & 62 & 6.2 \\
\hline High school & 30 & 3 \\
\hline Institute & 10 & 1 \\
\hline Bachelor & 44 & 4.4 \\
\hline Postgraduate & 6 & 0.6 \\
\hline Total & 1000 & $100 \%$ \\
\hline \multicolumn{3}{|l|}{ Mothers Occupation } \\
\hline House wife & 704 & 70.4 \\
\hline Government employee & 284 & 28.4 \\
\hline Retired & 12 & 1.2 \\
\hline Total & 1000 & $100 \%$ \\
\hline \multicolumn{3}{|l|}{ Monthly Income } \\
\hline Sufficient & 466 & 46.6 \\
\hline Insufficient & 534 & 53.4 \\
\hline Total & 1000 & $100 \%$ \\
\hline
\end{tabular}

Table represents the distribution of the mother's demographic data in term of frequencies and percentage. The mother's education, (39.6\%) mothers had primary school levels. Regarding mother's occupation, results indicated that the $(70.4 \%)$ of them were housewife. Concerning monthly income, the family income is enough or more than enough.

Table (3): Distribution of Study Sample by their Nutrition Status through Anthropometric Measurement (WAZ, HAZ, and WHZ)

\begin{tabular}{|l|c|c|}
\hline Nutrition Status Domain & Frequency N=1000 & Percentage \\
\hline Weight for age score & 770 & 77 \\
\hline Normal & 114 & 11.4 \\
\hline Overweight & 40 & 4 \\
\hline Obesity & 76 & 7.6 \\
\hline Underweight & $\mathbf{1 0 0 0}$ & $\mathbf{1 0 0 \%}$ \\
\hline Total & & \\
\hline
\end{tabular}




\begin{tabular}{|c|c|c|}
\hline Nutrition Status Domain & Frequency $N=1000$ & Percentage \\
\hline \multicolumn{3}{|l|}{ Height for age score } \\
\hline Normal & 658 & 65.8 \\
\hline Tall & 136 & 13.6 \\
\hline Stunting & 206 & 20.6 \\
\hline Total & 1000 & $100 \%$ \\
\hline \multicolumn{3}{|l|}{ Weight for Height score } \\
\hline Normal & 800 & 80 \\
\hline Overweight & 114 & 11.4 \\
\hline Obesity & 20 & 2 \\
\hline Wasting & 66 & 6.6 \\
\hline Total & 1000 & $100 \%$ \\
\hline
\end{tabular}

In assessing nutritional status by (WAZ): weight for age z scores, (HAZ): height for age z scores, and (WHZ): weight for height z scores. $\mathrm{F}=$ Frequency, $\%=$ Percentage

The findings revealed the distributions of the study sample according to the nutritional status indicators in term of WHZ, HAZ, and WAZ. Nutritional status is classified into three levels (underweight, normal, overweight and obesity) that concerning weight for age, (normal, tall and stunting) that concerning height for age. In concerning weight for height, the level includes (normal, overweight, obesity and wasting). In general, the proportion of normal weight recorded a higher percentage in first nutritional indicator $(77 \%)$ through assessing the weight for age. In assessing nutritional status by height for age the normal account $(65.8 \%)$. Regarding assessing nutritional status by weight for height indicators the table reveals that the results account $(80 \%)$ of children were normal.

\section{Discussion}

The preschool period is the period between 3 and 6 years of age, this is a time of continued growth and development. Physical growth continues much more slowly compared to earlier years. The average preschool age child will grow $(6.5-7.8 \mathrm{~cm})$ per year. The average 3 years old is $(96.2 \mathrm{~cm}$ tall), the average 4 years old is $(103.7 \mathrm{~cm}$ tall), and the average 5 years old is $(118.5 \mathrm{~cm}$ tall). Average weight gain during this time period is about $(2.3 \mathrm{~kg})$ per year. The average weight of a 3 years old is $(14.5 \mathrm{~kg})$, increasing to an average weight of $(18.6 \mathrm{~kg})$ by age $5^{(7)}$. The results in this work agree with the results obtained by other reposts such as ${ }^{(8)}$ who have studied nutritional status of under five children in Baghdad-
Iraq. Their findings indicate that the $(52.7 \%)$ of the study sample are male. Also this agree with the (rapid nutritional assessment survey carried out by UNICEF 2010-2011) which shows that (53\%)of children under 5 years are males. The present of underweight stunting and wasting in this study are similar in the finding of study conducted in Turkey the researchers found the prevalence's were $4.8 \%, 8.2 \%$ and 10,9 respectively ${ }^{(9)}$ these figures are lower than ours. But our findings are much lower than the findings gained by other researchers in different districts in many developing countries. In Nagpur who found that underweight, stunting and wasting $(46 \%, 52 \%$, and $20.7 \%){ }^{(10)}$.these variations between the findings of this study and other studies may be due to the variation in socioeconomic wellbeing status or the variations in the study designs and sample sizes. Our results are lower than that reported by a hospital based local study conducted by ${ }^{(11)}$. Regarding children age in the present study ranged from (0-47) months and above. The higher percentage of the sample is among age group (23-34) which constitutes (53\%) table (1). The World Health Organization estimates that malnutrition accounts for 54 percent of child mortality worldwide, in this age group was 1 million children every year. Another estimate also done by WHO states that childhood underweight is the cause for about $35 \%$ of all deaths of children under the age of five years worldwide ${ }^{(12)}$. These results are concurrent with the study which has been assessed relating to diet condition of kindergarten children: a socio-economic learning of 
rural area of Kasaragod District in Kerala. Their findings indicate that most children are in the age group (39-43) month ${ }^{(13)}$.

Study results depicted that the $(39.6 \%)$ of mothers had primary school levels of education table (2). A study has been tested relating to diet status of underneath five years' age children in Akure South Local Government, Ondo State, Nigeria. Their findings indicate that the most of mothers $(66 \%)$ are primary school educated and most of them are household. Results concludes that the mothers' education affected the health status of the children ${ }^{(14)}$. Concerning monthly income, most of families have been insufficient monthly income that account $(53.4 \%)$ which affects their socio-economic status table (2).

These results concurrent with the results reported by a study conducted on determinants of nutritional status in children under 5 years in India: A multilevel approach study. Their results indicate that the most of families making low socio-economic status and low income ${ }^{(15)}$. Socio-economic status particularly monthly income is an important factor that affects nutritional status in positive and negative terms, in an example regard the socio-economic status, a study has been tested factors affected HB and anemia among children. Their findings indicate that the families with low income may have a difficulty to buy food or medicines rich in iron or others need as recommended by the health care providers. Otherwise, families with high monthly income they will able to provides all the necessary food or others needs to treat the anemia, so the economic status is an important factor that will affects the HB level and others needs related to balance diet that protect the health of rapidly growing children under five ${ }^{(16)}$. As personal point of view, mothers as being employed to improved economic status of the family directly and higher economic status provide and facilitate all children's needs regarding nutrition, health care needs, education, family type, live in crowded or big families and all aspect of life. But mother employment some time affect child nutritional status negatively, because employed mothers spend many hours outside the house which reduce time for child care ${ }^{(17)}$.

\section{Conclusion}

The majority of study sample recorded normal nutritional status according to all three nutritional indicators; weight for age (WAZ), weight for height
(WHZ), and height for age (HAZ).Most of the mothers were primary school educated and more than half of them were housewife. Most of the fathers were highly educated and they were employed or have their own free work. Most demographic characteristics of parents and children have influenced their children nutritional condition.

Financial Disclosure: There is no financial disclosure.

Conflict of Interest: None to declare.

Ethical Clearance: All experimental protocols were approved under the Community Health Nursing, Nursing Departmentand all experiments were carried out in accordance with approved guidelines.

\section{References}

1. Al-Ghalebi, S.: Oral Health Status and Treatment Needs in Relation to Nutritional Status among 9-10 Year- old School Children in Nasiriya City/Iraq. Master thesis, College of Dentistry, University of Baghdad, 2011, p. 4.

2. Nutrition Ecology International Center. Under nutrition and malnutrition in the world. NEIC, Geneva; 2004.

3. WHO. Fact Sheet. 333. Geneva, Switzerland: World Health Organization; 2012. Newborn reducing mortality.

4. Pongou, R.;Ezzati, M. and Salomon, J.: Household and Community Socioeconomic and Environmental Determinants of Child Nutritional Status in Cameroon. Journal of Public Heath, 8 (2), 2006, p.p. 19-6.98.

5. Moshtak, W.: Assessment of Nutritional Status of Children in Al Hilla City. Journal of Natural Sciences Research, 3 (8), 2013, p.p. 172.

6. Edris, M.: Assessment of nutritional status of preschool children of Gumbrit, North WestEthiopia; Ethiop.Journal Health Dev.21(2), 2007, p.p. 345453.

7. Kyle, T.: Essential of Pediatric Nursing, 2018, p.p. 72,73,107,137, Lippincott Williams \& Wilkins company, China.

8. Nutrition Research Institute (NRI); Ministry of Health (MH) and UNICEF: Nutritional status survey of under five children In Baghdad - Iraq. 2013, p.3. 
9. Fernald, L. and Neufeld, L. Overweight with Concurrent Stunting in Very Young Children from Rural Mexico: Prevalence and Associated Factors. Clinical Journal of Nutrition, 61(5), 2007, p.p. 623-632.184.Food Security Analysis (FSA): A Comprehensive Analysis for Security Food. Nutritional Research Institute, 2008, p.p. 29- 27, 71.

10. Abushrayda AJ Malnutrition in children admitted to Karbala pediatric teaching hospital. Prevalence and associated risk factors, KufaMed.Journal; 2009..12(2.)

11. Pruss, A., Bos, R., Gore, F., Bartram, J. (2008). Safer water, better health - Costs, benefits and sustainability of interventions to protect and promote health. World Health Organization (WHO), Geneva, Switzerland.

12. Vipin, C.: Nutritional status of preschool children: a socio-economic study of rural areas of Kasaragod District in Kerala. Abstract of $\mathrm{PhD}$ thesis submitted to Kannur University for the award of degree of doctor of philosophy in economics, 2009, p.p. 1322.

13. Akorede. J. and Abiola, M.: Assessment of Nutritional Status of Under Five Children in AkureSouth Local Government, Ondo State, Nigeria. IJRRAS 14 (3), 2013, p.p. 671

14. Allison DB, Kaprio J, Korkeila M, Koskenvuo M, Neale MC, Hayakawa K. The heritability of Body Mass Index among an international sample of monozygotic twins reared apart. Int $\mathrm{J}$ Obes. 1996;20(6):501-506.

15. Salive, R. and Alston. M.: Families of Nutritional status and Economic Association. IJRRAS, 2 (9), 2009, p.p. 174-216.

16. Rahman, M.;Mostofa, G.;Nasrin, S.: Nutritional Status among Children Aged 24-59 Months in Rural Bangladesh: An assessment measured by BMI index. International Journal of Anthropometrics, 3(1), 2009, p. 18. 